\title{
A passive islanding detection method for hybrid distributed generation system under balanced islanding
}

\author{
K. Suresh ${ }^{1}$, P. Anusha ${ }^{2}$, Sk. Najma ${ }^{3}$, B. I. Rajkumar ${ }^{4}$, Ch. Rami Reddy ${ }^{5}$, B. Prasanna Lakshmi ${ }^{6}$ \\ 1,2,3,4,5 Department of Electrical and Electronics Engineering, Nalanda Institute of Engineering and Technology, \\ Sattenapalli, Guntur, India \\ ${ }^{6}$ Department of Electronics and Communication Engineering, Nalanda Institute of Engineering and Technology, \\ Sattenapalli, Guntur, India
}

\begin{tabular}{|c|c|}
\hline Article Info & ABSTRACT \\
\hline $\begin{array}{l}\text { Article history: } \\
\text { Received Jun 1, } 2018 \\
\text { Revised Dec 21, } 2018 \\
\text { Accepted Jan 25, } 2019\end{array}$ & $\begin{array}{l}\text { To solve the energy consumption demand of the world and environmental } \\
\text { problems in the future the distributed generation is considered an alternative } \\
\text { approach. In this paper a new passive islanding detection technique was } \\
\text { proposed for the Hybrid distributed generation (HDG) system based on } \\
\text { changes in negative sequence voltage (NSV) and currents during an }\end{array}$ \\
\hline $\begin{array}{l}\text { Keywords: } \\
\text { Balanced islanding, } \\
\text { Hybrid distributed generation } \\
\text { (HDG) } \\
\text { Islanding detection } \\
\text { Negative sequence voltage } \\
\text { (NSV) } \\
\text { Non detection zone }\end{array}$ & $\begin{array}{l}\text { system due to failures in the power grid. As per distribution energy resources } \\
\text { interconnection standards, it should be detected within } 2 \text { sec with the } \\
\text { equipments connected to it. It is difficult to detect islanding during zero } \\
\text { power imbalance condition. Sequence analyzer will separate the positive, } \\
\text { negative and zero sequence components of voltages and currents from the } \\
\text { voltages and currents obtained at the point of common coupling (PCC). } \\
\text { During a wide range of power imbalance conditions the change in negative } \\
\text { sequence voltage and currents are examined for islanding detection. The } \\
\text { simulation shows that this method is free from Non detection zone, even at } \\
\text { zero power imbalances between load and distribution generation. The } \\
\text { computer simulations made in Matlab/ Simulink laboratory show the } \\
\text { effectiveness of this method. }\end{array}$ \\
\hline
\end{tabular}

Copyright $(2019$ Institute of Advanced Engineering and Science. All rights reserved.

\section{Corresponding Author:}

Ch. Rami Reddy,

Department of Electrical and Electronics Engineering

Nalanda Institute of Engineering and Technology

Sattenapalli, Guntur, Andhra Pradesh, India. 522403.

Email: crreddy229@gmail.com

\section{INTRODUCTION}

Nowadays, the global energy demand is supplied by the combustion of fossil fuel resources. Due to continuous combustion of fossil fuels the environment is affecting and fossil fuels are decreasing. So the alternate solution for global energy consumption demand and pollution free country is the use of renewable energy resources like solar, wind, etc. Distributed generation is the smallest scale power generation source which is connected at the consumer level of power system [1]. Most of the DG systems are using renewable energy resources and interfaced to the grid with suitable power converters. Depending on the nature of the source the energy may be generated in AC or DC forms. The main problems with such renewable power generation are an unintentional islanding. Due to failures in the grid, if the DG is disconnected from the main grid, the DG along with local load forms an islanding [2]. The islanding is unsafe to field persons and equipments connected because the servicing persons are not mindful that the frame up is connected and supplying with DG near. The main causes of such unintentional islanding are due to the failures detected by the grid, accidental opening of circuit breakers at the grid, intentional opening of $\mathrm{CB}$ for maintenance, human errors and an act of nature [3]. The basic grid interfacing rules such as IEEE 1547 and UL 1741 needs that, it 
is necessary to disconnect the DG source within 2 seconds after islanding, because it leads to variations in the voltage, frequency, current, THD, active, reactive powers outside the standards, which may hazardous to customers and loads connected to it [4-5]. Different control systems and inverters are implemented to connect DG sources to grid with proper synchronization and to inject high quality power into the grid [6-7]. The islanding detection methods are classified as local islanding detection methods and remote islanding detection methods. PLCC and SCADA are the remote islanding detection techniques; they detect the islanding by gathering information from DG side and utility side. Utility side signals are monitored by the PLCC [8-9]. If these signals are not appearing then islanding is detected. On the other hand, islanding was detected by SCADA with information from circuit breaker auxiliary contacts. The implementation of these methods is very difficult because the cost and implementation of other monitoring devices such as transmitters and receivers are more [10]. The local islanding detection methods are again classified as passive, active, and Hybrid islanding detection methods [11-12]. By injecting some signal at PCC for some cycles and observing the deviations in the output signal active methods will detect the islanding. In the grid connected system, the system absorbs the local disturbance and considerable deviations are not observed. However, more deviations are observed in the output signal if the system is islanded [13-17]. By observing these deviations the islanding is detected by active methods. The active methods are more efficient than passive methods, but they reduce the power quality [18-19]

The low frequency current injected through the DQ controller of inverter based distributed generation presented will work inside the NDZ of a conventional frequency relay [20-23]. Large samples of data collected from non-islanding and islanding events such as voltage, current, power, P.f, etc. and processing it with the learning algorithms, the islanding is detected by machine learning detection techniques. Some popular algorithms such as Artificial Neural Networks (ANN) [24], Decision Tree Models (DT) [25], and Support Vector Machines (SVM) [26] are used to differentiate between islanding and non islanding incidents. In passive techniques, regional parameters such as voltage, frequency, current, phase jump, active power, reactive power and other are monitored at the PCC, if their changes are beyond a certain threshold level, then islanding is detected [27-32] The over/ under frequency relay works when the frequency is more or less than 50.5 and 49.5 as per Indian standards [28]. Hybrid methods use the combination of active and passive methods. If the islanding is suspected by passive method, the active method will confirm the islanding. These methods have less NDZ but they are affected by poor power quality [33-39]. The passive techniques are suffering with large NDZ, but they are simple to implement. In this paper a new passive islanding detection method is implemented with zero NDZ with change in NSV and currents. The differentiated signals of voltages and currents from sequence analyzer are compared with predefined values and islanding is detected if they are beyond a threshold value. This method is simple and free from NDZ. This method detects islanding even at the zero power imbalance condition quickly than other methods. The rest of the paper is organized as follows. System under the study along with control system is discussed in Section II, The proposed change in NSV method III, The simulated results, and comparison with the existing methods are presented in section IV, and conclusions are drawn in Section V.

\section{SYSTEM UNDER STUDY}

The test system shown in Figure 1 is simulated with the Sim-power systems environment to show the performance of the proposed method. The test system is designed with IEEE 1547 and UL 1741 [4-5] series standards. This hybrid distributed generation system consisting of three different sources of solar, wind and storage battery. The PV panel is designed with sun power modules (SPR-305). Five series connected parallel modules of 66 strings are connected to produce a rated power of $1 \mathrm{kw} / \mathrm{m}^{2}$ as the temperature is abnormal. The thevinions voltage and Norton's currents of each module are 64.2 volts and 5.96 amperes respectively. The output of the PV array is connected to DC/DC boost converter, whose duty cycle is controlled by maximum power point tracking (MPPT) controller to extract maximum power. A Wind farm of $9 \mathrm{MW}(6 * 1.5 \mathrm{MW})$ with doubly fed induction generator is considered. Wind turbines using a Doubly-fed Induction generator (DFIG) consist of a wound rotor Induction generator followed by a boost converter. The DFIG technology allows extracting maximum power from the wind for low wind speeds by optimizing the turbine speed, while minimizing mechanical stresses on the turbine during gusts of wind. The outputs of both boost converters and battery are connected to the DC bus. The DC voltage from DC bus is synchronized to the grid with synchronous rotating reference frame controller through three phase inverter, LC filter and step up transformer. The synchronous rotating reference frame controller shown in Figure 2 [6] will control the amount of active power delivered to the grid, reactive transferring between grid and Hybrid system, DC link voltage, and proper synchronization to grid with good power quality [6-9]. The three phase circuit breaker (CB) at PCC is switched to create the islanding condition. Before opening of the CB the hybrid DG system is in the grid connected mode. By opening the $\mathrm{CB}$, the hybrid DG along the local load forms an islanding 
condition. Now the DG itself supplies the load demanded power under worst case of islanding situation which means zero power imbalance between generation and load capacity.

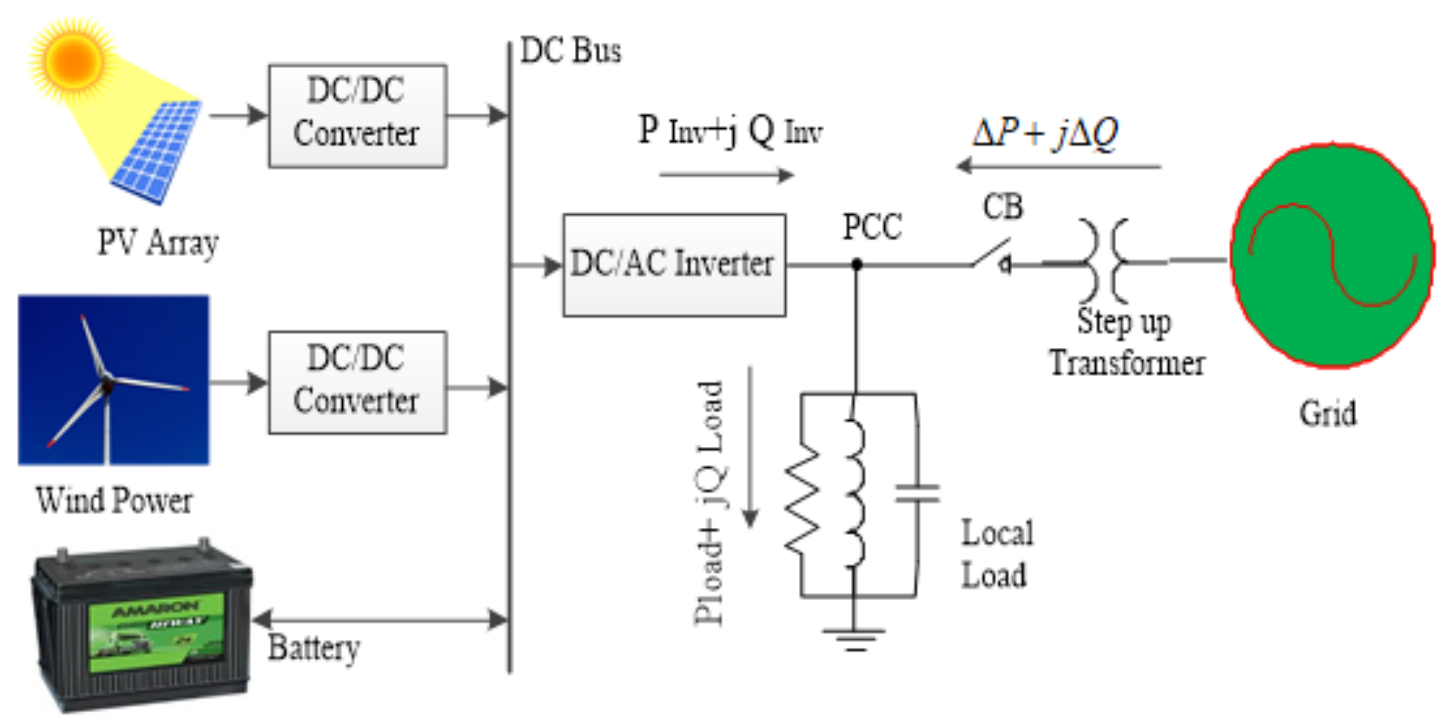

Figure 1. Block diagram of the Hybrid distributed generation system under study

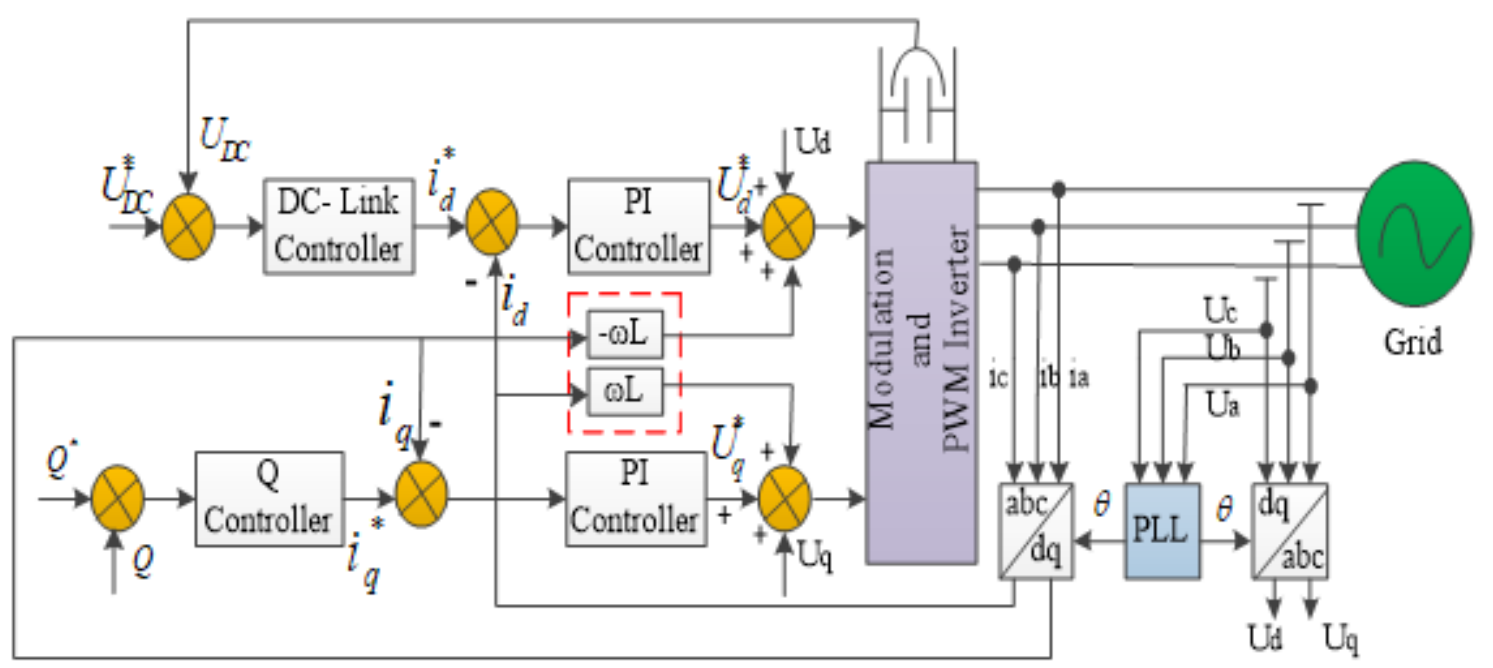

Figure 2. Control system used for grid integration of Hybrid energy resources

\section{PROPOSED ISLANDING DETECTION METHOD}

The hybrid energy sources are integrated with the grid with rotating reference controller shown in Figure 2 will gives balanced voltages and currents at PCC in the grid connected mode. The balanced voltages and currents at PCC are equal in magnitude and $120^{\circ}$ apart from each other. During islanding the voltages and currents are unbalanced. The sequence analyzer will separate the positive, negative and zero sequence components from unbalanced voltages and currents obtained at PCC. The zero sequence components present only when the system is associated with ground. The negative sequence components present during the islanding operation. The positive sequence components will present in all modes. The symmetrical components of voltages are at PCC are defined as (1). 
$\left[\begin{array}{c}v_{a 0} \\ v_{a 1} \\ v_{a 2}\end{array}\right]=\frac{1}{3}\left[\begin{array}{ccc}1 & 1 & 1 \\ 1 & \alpha^{2} & \alpha \\ 1 & \alpha & \alpha^{2}\end{array}\right]\left[\begin{array}{c}v_{a} \\ v_{b} \\ v_{c}\end{array}\right]$

The symmetrical components of currents are defined as

$\left[\begin{array}{c}i_{a 0} \\ i_{a 1} \\ i_{a 2}\end{array}\right]=\frac{1}{3}\left[\begin{array}{ccc}1 & 1 & 1 \\ 1 & \alpha^{2} & \alpha \\ 1 & \alpha & \alpha^{2}\end{array}\right]\left[\begin{array}{c}i_{a} \\ i_{b} \\ i_{c}\end{array}\right]$

Where $v_{a 0}, v_{a 1}$ and $v_{a 2}$ are the zero sequence, positive sequence and negative sequence voltages. $i_{a 0}, i_{a 1}$ and $i_{a 2}$ are the zero sequence, positive sequence and negative sequence currents. $v_{a}, v_{b}, v_{c}$ and $i_{a}, i_{b}$ and $i_{c}$ are the three phase voltages and currents at PCC

$\alpha=1 \angle 120^{\circ}$ or $\quad \cos 120^{\circ}+\mathrm{j} \sin 120^{\circ}$

and also $\alpha^{2}+\alpha+1=0$

The sequence components of voltages and currents are

$$
\begin{aligned}
& v_{a 1}=\frac{1}{3}\left(v_{a}+\alpha v_{b}+\alpha^{2} v_{c}\right) \\
& v_{a 2}=\frac{1}{3}\left(v_{a}+\alpha^{2} v_{b}+\alpha v_{c}\right) \\
& v_{a 0}=\frac{1}{3}\left(v_{a}+v_{b}+v_{c}\right) \\
& i_{a 1}=\frac{1}{3}\left(i_{a}+\alpha i_{b}+\alpha^{2} i_{c}\right) \\
& i_{a 2}=\frac{1}{3}\left(i_{a}+\alpha^{2} i_{b}+\alpha i_{c}\right) \\
& i_{a 0}=\frac{1}{3}\left(i_{a}+i_{b}+i_{c}\right)
\end{aligned}
$$

The change in negative sequence voltage and currents can be written as

Change in negative sequence voltage is $\frac{d V_{a 2}}{d t}$

Change in negative sequence current is $\frac{d i_{a 2}}{d t}$

by observing the rate of change of NSV and rate of change of Negative sequence current (NSC) the islanding is detected. In the grid connected mode these deviations are not present, but in islanding condition these changes are more and an islanding is detected. 


\section{SIMULATION RESULTS AND DISCUSSION}

The Hybrid distribution generation system shown in Figure 1 is implemented using MATLAB 2017/ Simulink model. Different islanding and non islanding events studied are 1. Grid connected mode 2. Islanding mode with different active power mismatches, and 3. A non islanding case of load switching

\subsection{Grid connected mode}

The C.B is closed in the grid connected mode. The simulated results of voltages, currents, active power and reactive power under steady state as shown in Figure 3. The DC link voltage, frequency is shown in Figure 4.
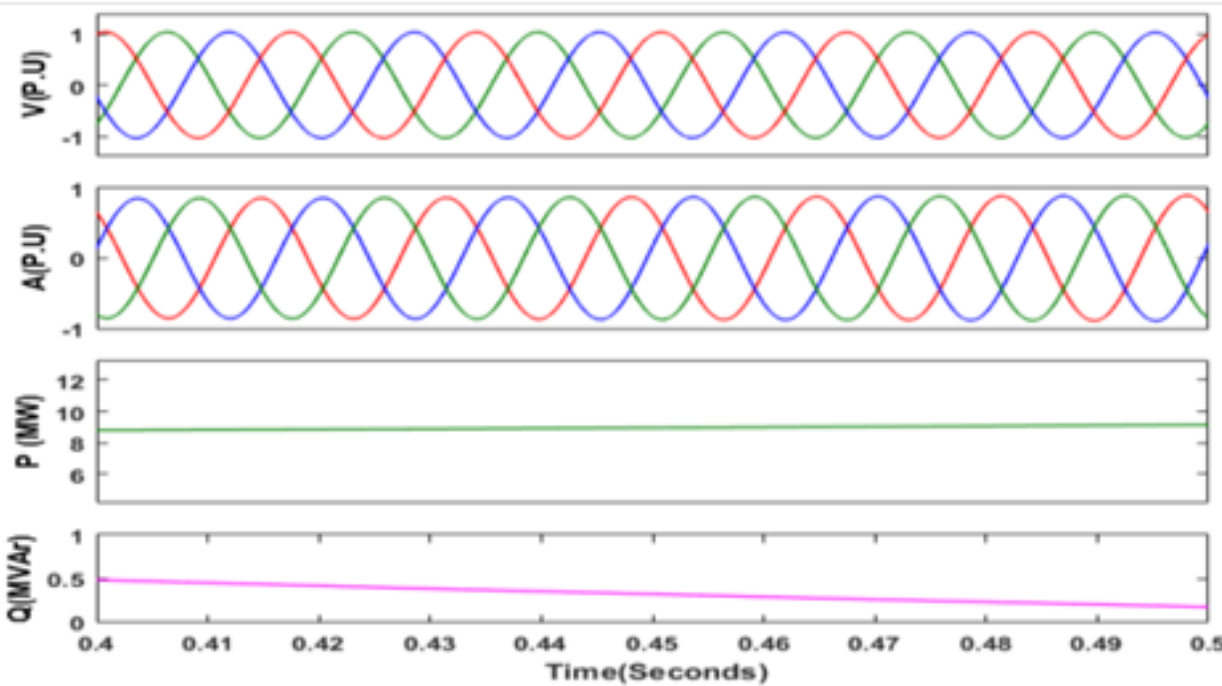

Figure 3. Voltages, currents, Active power and Reactive power in grid connected operation

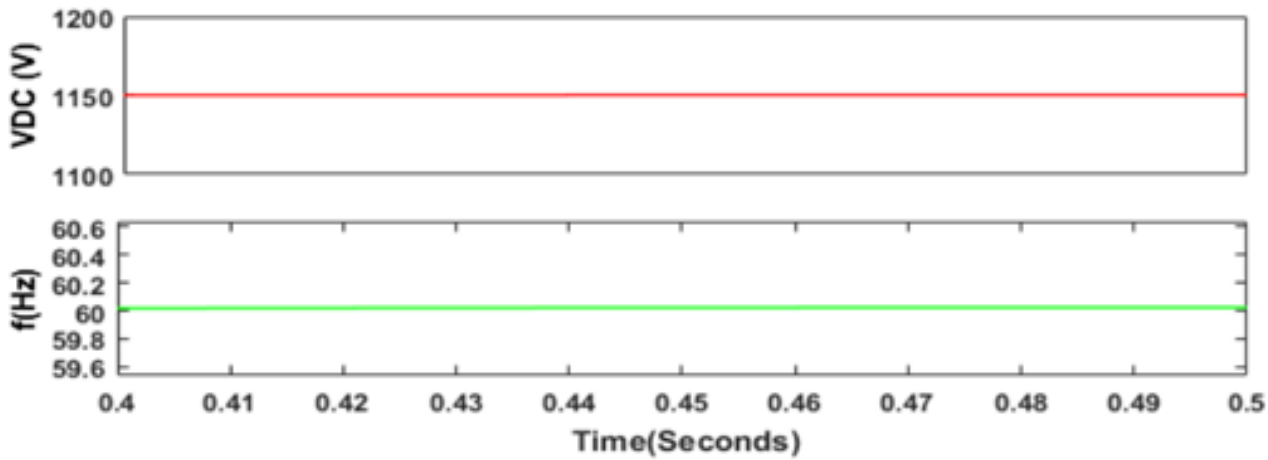

Figure 4. DC link voltage and frequency in grid connected operation

The positive, negative and zero sequence voltages in the grid connected operation are shown in Figure 5, the negative sequence and zero sequence voltages are zero and only positive sequence component is present in the grid connected mode. 


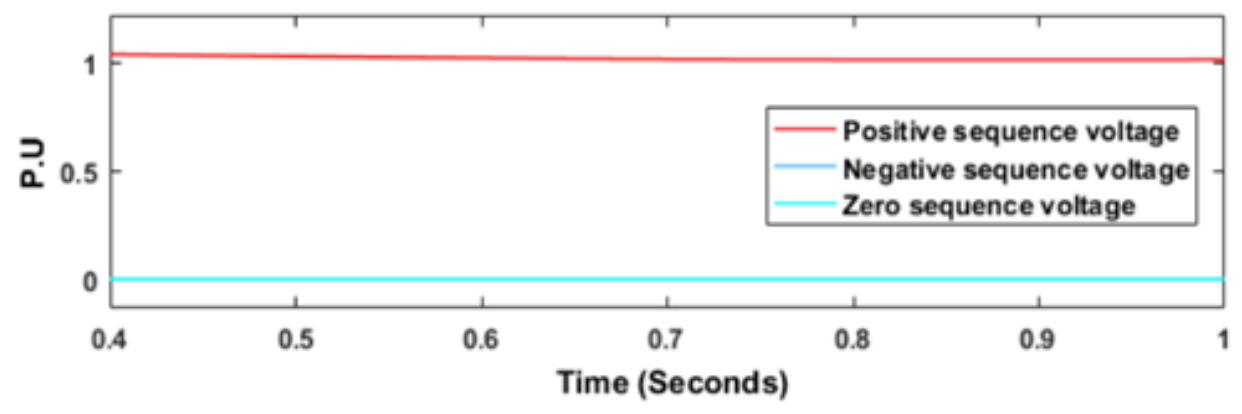

Figure 5. Positive, negative and zero sequence voltages in grid connected operation

\subsection{NSV and rate of change of NSV during grid connected, islanding, load switching and at different active power imbalance conditions}

During the grid connected mode only the positive sequence component of voltages is present, negative and zero sequence components are zero. In the islanding condition and fault conditions negative sequence voltages are present. The negative sequence voltages at PCC during grid connected and islanding modes are shown in Figure 6 , at $t=0.5$ the islanding is initiated by opening the C.B and shows that the changes in negative sequence voltages are more compared to zero in the grid connected mode. The negative sequence voltage at PCC with load switching and islanding modes are shown in Figure 7, shows that the oscillations in negative sequence voltages during load switching are nil compared to the system working in islanding mode. The rate of change of NSV during grid connected, islanding, and load switching are shown in Figure 8.

The deviations in the rate of change of NSV during grid connected and load switching is very less and more in islanding condition. So by setting a threshold value of the rate of change of NSV at $5 \mathrm{p} . \mathrm{u} / \mathrm{sec}$, the islanding is smoothly detected and tripping signal is forwarded for the protection of hybrid distributed generation system. The most passive islanding detection techniques cannot detect islanding if the power imbalance is less than $15 \%$. The rate of change of NSV with different power imbalances is From Figure 9, the proposed method can detect islanding at very low and zero power imbalance situations within $80 \mathrm{~ms}$ and oscillations at different power imbalance conditions are nearly same, and it is the most effective method to detect islanding at zero power imbalance condition.

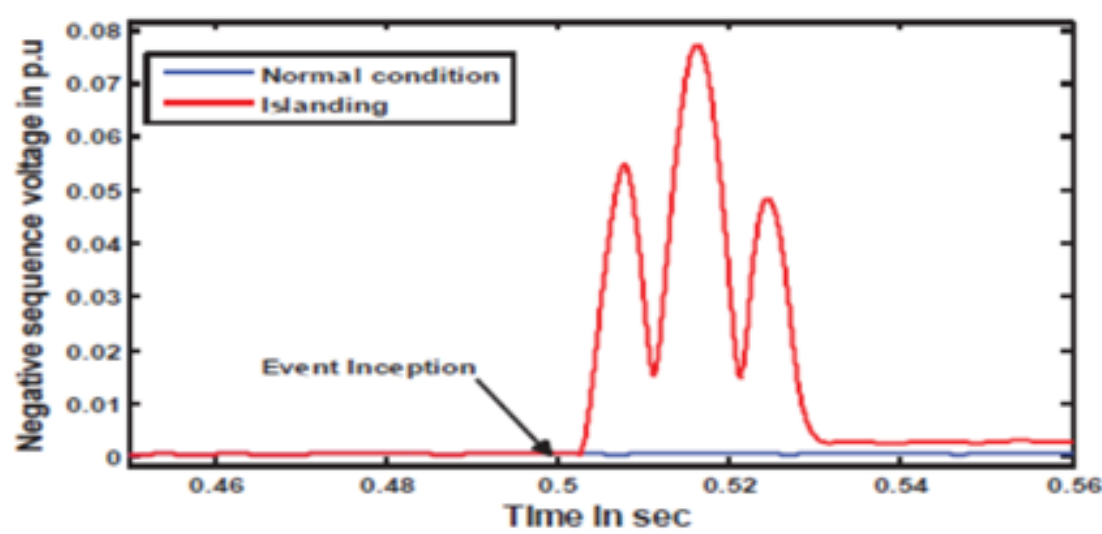

Figure 6. NSV during grid connected and islanding modes 


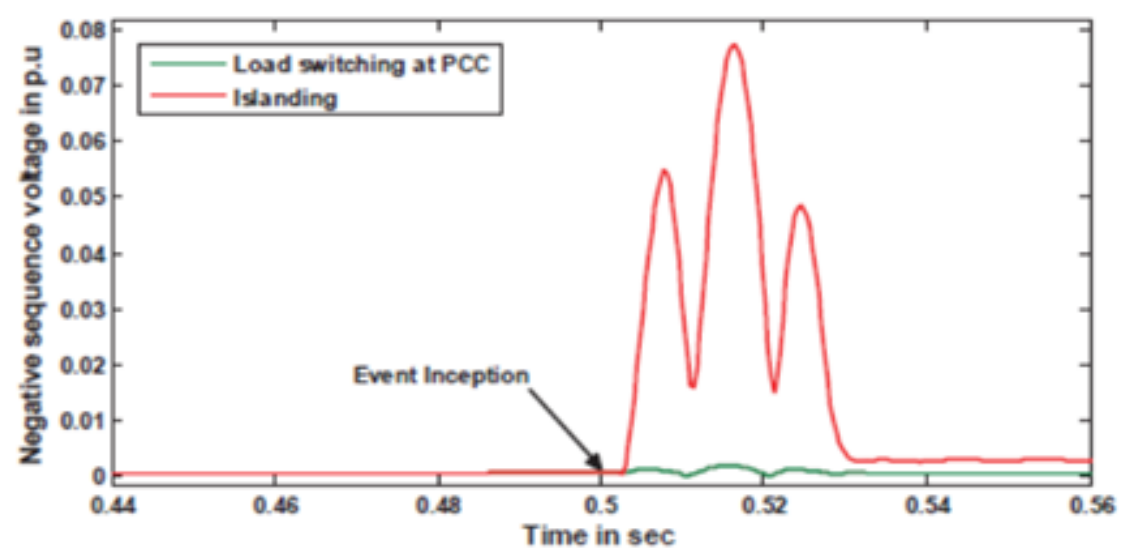

Figure 7. NSV during Lad switching and islanding modes

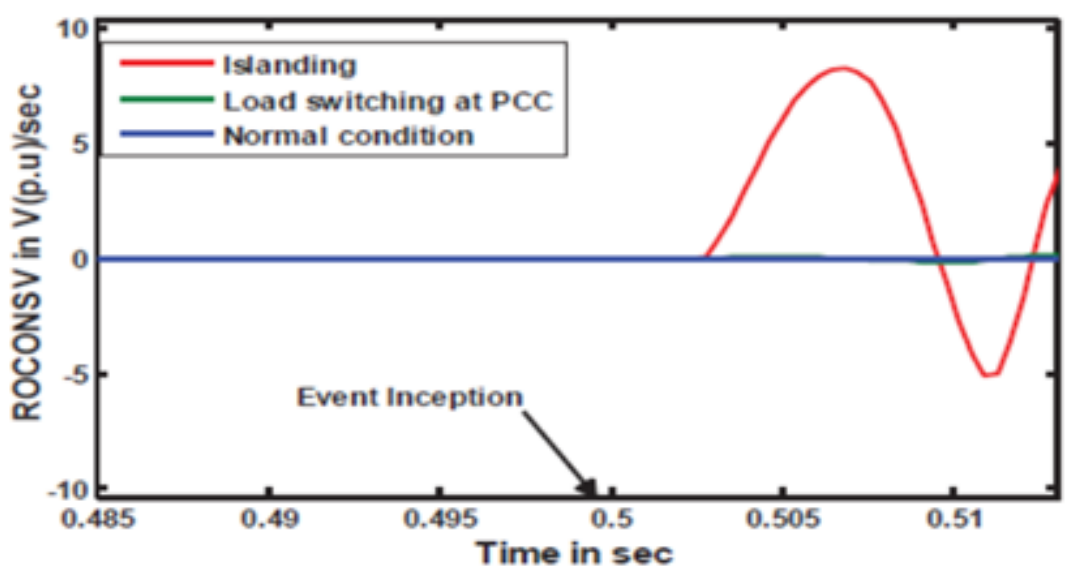

Figure 8. Rate of change of NSV During grid connected, islanding and load switching condition

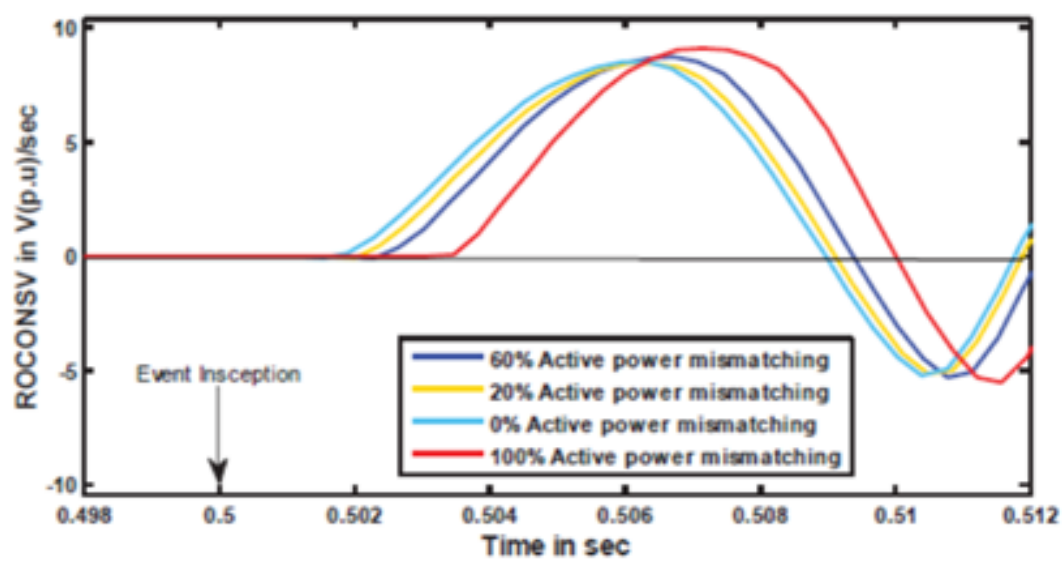

Figure 9. Rate of change of NSV at different active power imbalances

4.3 NSC and rate of change of NSC during grid connected, islanding, load switching and at different active power imbalance conditions

In the islanding condition and fault conditions negative sequence currents are present while in the grid connected mode they are not available. The negative sequence currents at PCC during grid connected 
and islanding modes are shown in Figure 10, at $\mathrm{t}=0.5$ the islanding is initiated by opening the C.B and shows that the changes in negative sequence currents are more compared to zero in the grid connected mode. The negative sequence currents at PCC during load switching and islanding modes are shown in Figure 11, shows that the oscillations in negative sequence currents during load switching are nil compared to the system working in islanding mode. The rate of change of NSC during grid connected, islanding, and load switching are shown in Figure 12, The deviations in the rate of change of NSC during grid connected and load switching is very less and more in islanding condition. So by setting a threshold value of the rate of change of NSC at $10 \mathrm{p.u} / \mathrm{sec}$, the islanding is smoothly detected and tripping signal is forwarded. The rate of change of NSC with different power imbalances is from Figure 13, the proposed method can detect islanding at very low and zero power imbalance situations also within $80 \mathrm{~ms}$ and oscillations at different power imbalance conditions are nearly same, and it is the most effective method to detect islanding at zero power imbalance condition.

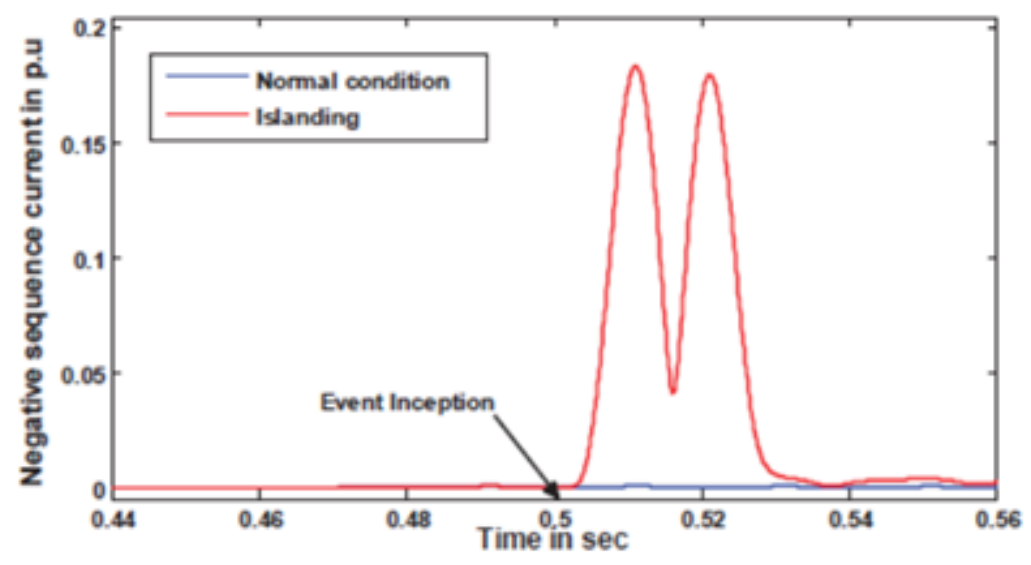

Figure 10. NSC during grid connected and islanding modes

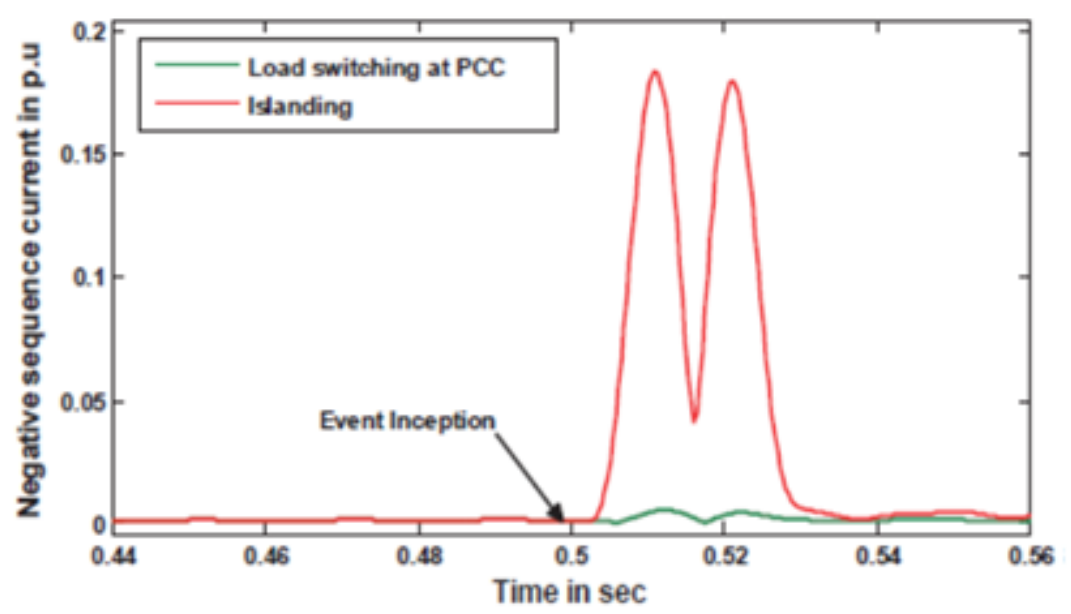

Figure 11. NSC during Load switching and islanding modes 


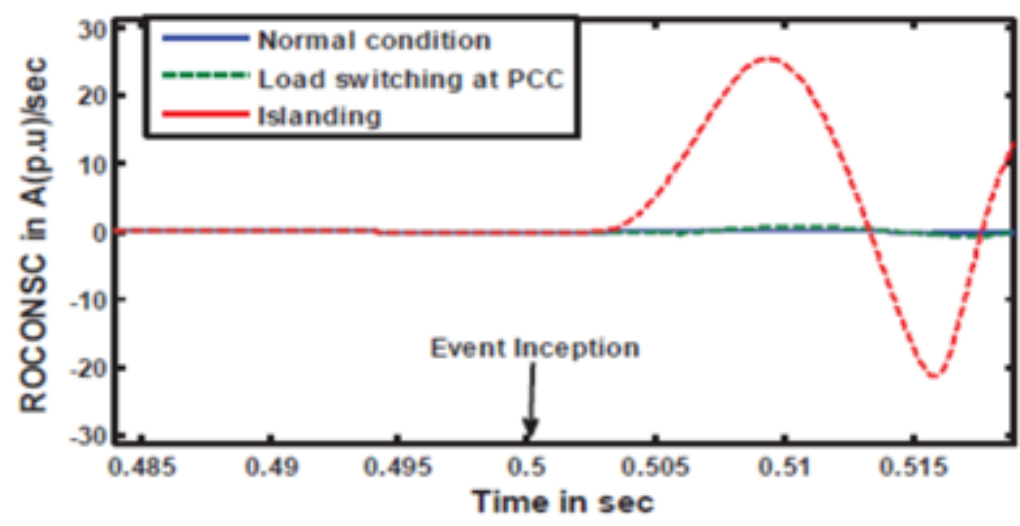

Figure 12. Rate of change of NSC During grid connected, islanding and load switching condition

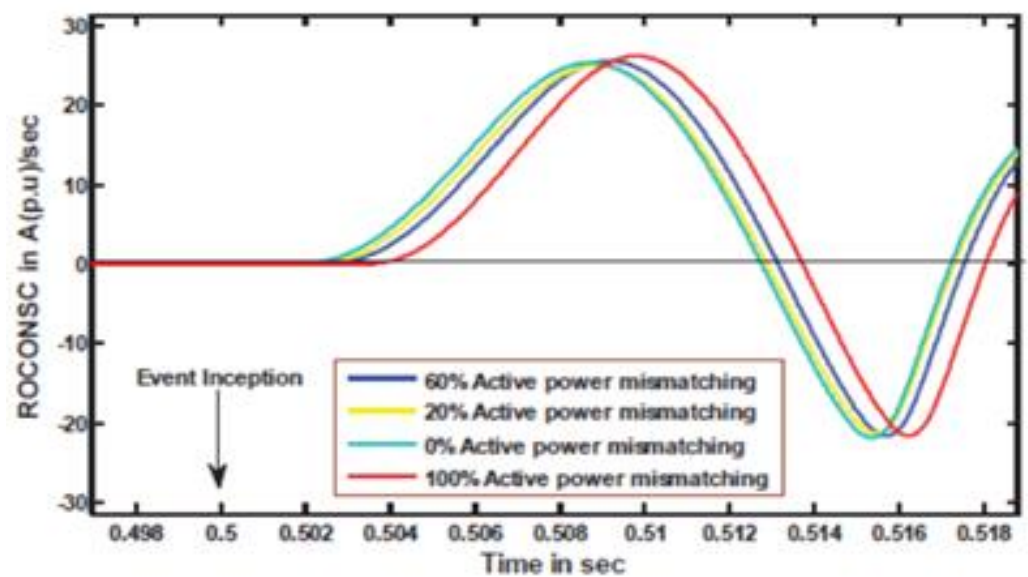

Figure 13. Rate of change of NSC at different active power imbalances

\subsection{Comparison with existing passive methods}

In this part of the paper the existing passive islanding detection methods are compared with the proposed methods. Almost all passive islanding detection methods fail to detect islanding during zero power imbalance conditions and the NDZ is large some of which are shown in Table 1. The proposed method can detect islanding within $80 \mathrm{~ms}$ even at zero power imbalance conditions and this method is completely free from the NDZ.

Table 1. Comparison of existing passive islanding detection methods

\begin{tabular}{lcc}
\hline \multicolumn{1}{c}{ Passive Islanding detection method } & NDZ & Detection Time \\
\hline Voltage and current harmonic detection & Large with a large value of Q & 200 to $300 \mathrm{~ms}$ \\
Over under voltage/ over under frequency OUV/ OUF & Large & $400 \mathrm{~ms}$ to $2 \mathrm{~s}$ \\
Rate of change of frequency (ROCOF) & Small & $300 \mathrm{~ms}$ \\
Rate of change of frequency over power (ROCOP) & Smaller than ROCOF & $250 \mathrm{~ms}$ \\
Rate of change of power (ROCOP) & Smaller than OUV/OUF & $400 \mathrm{~ms}$ \\
Phase Jump Detection (PJD) & Large & $100-200 \mathrm{~ms}$ \\
Voltage Unbalance (VU) & Large & $100 \mathrm{~ms}$ \\
\hline
\end{tabular}

\section{CONCLUSION}

To overcome the problems with unintentional islanding, a new passive islanding detection method is presented in this paper with rate of change of NCS and rate of change of NSV. Most of the passive islanding detection methods fail to detect islanding at zero power imbalance condition. This method is working efficiently during zero power imbalance condition which is the worst case of islanding and detecting 
islanding within $80 \mathrm{~ms}$. This method is free from NDZ. This method was clearly differentiating between islanding and non islanding events.

\section{REFERENCES}

[1] Ashok Bindra "A Unified Interface for Integrating Renewable Energy Sources with the Smart Grid”, IEEE Power Electronics Magazine, vol. 3, no. 4, pp: 4-6, 2016.

[2] Yu Zheng; Zhao Yang Dong; Ke Meng; Hongming Yang; Mingyong Lai; Kit Po Wong "Multi-objective distributed wind generation planning in an unbalanced distribution system" CSEE Journal of Power and Energy Systems, Volume: 3, Issue: 2,Pages: 186 - 195, Year: 2017.

[3] Ch Rami Reddy, K Harinadha Reddy "Islanding Detection using DQ Transformation based PI Approach in Integrated Distributed Generation”, International Journal of Control Theory and Applications, volume: 10, issue: 5 , pp. 679-690, 2017.

[4] Thomas Basso; Sudipta Chakraborty; Andy Hoke; Michael Coddington "IEEE 1547 Standards advancing grid modernization” IEEE 42nd Photovoltaic Specialist Conference, Pages: 1 - 5, Year: 2015

[5] "UL1741 standard for safety for static converters and charge controllers for use in photovoltaic power systems," Underwriters Laboratories, Jan 2001.

[6] Yash P. Bhattl and Mihir C. Shah "Design, Analysis and Simulation of Synchronous Reference Frame based Phase Lock Loop for Grid Connected Inverter", IEEE International Conference on Power Electronics Intelligent Control and Energy Systems, pp. 1-5, 2016.

[7] Joydip Jana, Hiranmay Saha, Konika Das Bhattacharya "a review of inverter topologies for single phase grid connected photovoltaic systems”, Renewable and Sustainable Energy reviews, vol. 72, pp. 1256-1270, 2017.

[8] Giovanni Artale; Antonio Cataliotti; Valentina Cosentino; Dario Di Cara; Salvatore Guaiana; Salvatore Nuccio; Nicola Panzavecchia; Giovanni Tinè "Smart Interface Devices for Distributed Generation in Smart Grids: The Case of Islanding” IEEE Sensors Journal, Volume: 17, Issue: 23, Pages: 7803 - 7811, 2017.

[9] GökayBayrak n, ErsanKabalci "Implementation of a new remote islanding detection method for wind-solar hybrid power plants" Renewable and Sustainable Energy Reviews 58, pp.1-15, 2016.

[10] Subhra J. Sarkar; Palash K. Kundu "A proposed method of load scheduling and generation control using GSM and PLCC technology” Michael Faraday IET International Summit, pp: 273 - 277, 2015.

[11] Jimmy Y. Zhang; Cameron M. Bush "PMU based islanding detection to improve system operation" IEEE Power and Energy Society General Meeting, pp. 1 - 5, 2016.

[12] Ch. Rami Reddy, K. Harinadha Reddy "Islanding detection for inverter based distributed generation with Low frequency current harmonic injection through Q controller and ROCOF analysis", Journal of Electrical Systems, volume: 14, issue: 02, pp: 179-191, 2018.

[13] P. Gupta, R. Bhatia, and D. Jain, "Average absolute frequency deviation value based active islanding detection technique," IEEE Transactions on Smart Grid, vol. 6, no. 1, pp. 26-35, Jan 2015

[14] Ke Jia, Hongsheng Wei, Tianshu Bi, David Thomas and Mark Sumner "An Islanding Detection Method for MultiDG Systems Based on High Frequency Impedance Estimation ” IEEE Transactions on sustainable energy, Volume: 8, no. 7 pp: $74-83,2017$.

[15] Suman Murugesan; Venkatakirthiga Murali; S. Arul Daniel "Hybrid Analyzing Technique for Active Islanding Detection Based on d-Axis Current Injection” IEEE Systems Journal, vol. pp, no. 99, pp. 1$10,2017$.

[16] Zhongwei Guo "A harmonic current injection control scheme for active islanding detection of grid-connected inverters" IEEE International Telecommunications Energy Conference, pp: 1 - 5, 2015.

[17] Snehamoy Dhar, Sheetal Chandak; M H Naeem "Harmonic profile injection based active islanding detection for PV-VSC based grid", IEEE Power Communication and Information Technology Conference,Pages: 489 496, 2015.

[18] Aref Pouryekta; Vigna K. Ramachandaramurthy; Jeyraj Selvaraj "Active islanding detection for synchronous generators using speed disturbance injection technique" IEEE Conference on Clean Energy and Technology, pp: 54 - 59,2013 .

[19] Tai-Zhou Bei "Erratum: Accurate active islanding detection method for grid-tied inverters in distributed generation” IET Renewable Power Generation, Volume: 11, Issue: 13, Pages: 1731 - 1731, 2017.

[20] Pankaj Gupta; Ravinder Singh Bhatia; Dinesh Kumar Jain "Islanding detection of active distribution system with parallel inverters" IEEE International Conference on Signal Processing, Informatics, Communication and Energy Systems, Pages: 1 - 5, 2017.

[21] K. V. Siva Reddy, SK. Moulali, K. Harinadha Reddy, Ch. Rami Reddy, B. V. Rajanna, G. Venkateswarlu, Ch. Amarendra "Resonance Propagation and Elimination in Integrated and Islanded Micro grids", International Journal of Power Electronics and Drive System, volume:9, issue: 3, pp. 1445-1456, 2018

[22] Ch. Rami Reddy, K. Harinadha Reddy "A Passive Islanding Detection method for Neutral point clamped Multilevel Inverter based Distributed Generation using Rate of Change of Frequency Analysis” International journal of electrical and computer engineering , volume: 08, issue: 04, pp:1967-1976, 2018.

[23] Ali Emadi; Hosein Afrakhte; Javad Sadeh "Fast active islanding detection method based on second harmonic drifting for inverter-based distributed generation" IET Generation, Transmission \& Distribution, Volume: 10, Issue: 14,Pages: 3470 - 3480, 2016. 
[24] S. Salman, D. King, and G. Weller, "Investigation into the development of a new ANN-based relay for detecting loss of mains of embedded generation," in IEEE International Conference on Developments in Power System Protection, vol. 2, pp. 579-582 Vol.2, April 2004.

[25] O. Faqhruldin, E. El-Saadany, and H. Zeineldin, "A universal islanding detection technique for distributed generation using pattern recognition”, IEEE Transactions on Smart Grid, vol. 5, no. 4, pp. 1985-1992, July 2015.

[26] B. Matic-Cuka and M. Kezunovic, "Islanding detection for inverter based distributed generation using support vector machine method", IEEE Transactions on Smart Grid, vol. 5, no. 6, pp. 2676-2686, Nov 2014.

[27] Abhilasha Kumari; Rupendra Kumar Pachauri; Yogesh K. Chauhan "Passive islanding detection approach for inverter based DG using harmonics analysis" IEEE 1st International Conference on Power Electronics, Intelligent Control and Energy Systems, Pages: 1 - 6, 2016.

[28] Ch. Rami Reddy, K. Harinadha Reddy "Islanding detection method for inverter based distributed generation based on combined changes of ROCOAP and ROCORP" International journal of pure and applied mathematics, volume: 117, issue:19, pp: 433-440, 2017.

[29] Ch Rami Reddy, K Harinadha Reddy "Recognition of islanding data for multiple distributed generation systems with ROCOF shore up analysis", Smart Intelligent Computing and Applications, volume: 104, pp: 547-558, 2019. 